\title{
Bearing and Spreading of Cultural Connotation of Animation Public Education Short Film in the New Media Era
}

\author{
Bing Wang ${ }^{\mathrm{a}}$, Yao $\mathrm{Xu}^{\mathrm{b}}$, Wuming $\mathrm{Ma}^{\mathrm{c}}$ \\ Institute of Information Communication Engineering, Changchun University of Technology, \\ Changchun 130012, China \\ a1634256252@qq.com, b1763974129@qq.com, '670605910@qq.com
}

\begin{abstract}
China has entered the new millennium, science and technology have driven the rapid development of new media industry. The development of new media has brought new opportunities for China's animation public welfare education short film industry. China's animation public welfare education short film environment is excellent, but at the same time, we have to admit that China's animation public welfare education short film also faces some problems at this stage, which restrict the animation public welfare short The development of the film, therefore, we need to explore in-depth, hoping to improve our animation public welfare education, to contribute their own ideas.
\end{abstract}

Keywords: animation; public welfare; educational short film.

\section{Introduction}

With the continuous improvement of people's material living standards, the audience's aesthetic needs for audio-visual art works of digital media are also changing. Film and television enthusiasts and artists are gradually looking for the boundary of art, combining the exaggerated animation image with the "micro" expression under the new media, supplemented by the concept of public welfare, that is, the animation public education short film follows the trend and emerges as the times require.

\section{Definition of Animation Public Service Advertisement}

Animation public welfare education short film refers to the use of modern artistic expression, with the animation production method, using the narrative form of micro film for reference, enriching the longitude and latitude of the public audio-visual, achieving the social public publicity activities for the purpose of non-profit, so as to achieve the social life attitude of edification, education, law-abiding, selfless for the people, and spreading the positive energy of the society.

Under the new media environment, animation public education short film has the characteristics of short and concise, exaggerated humor, virtual diversity, low cost and high effect. Animation public education short film adapts to the new media transmission. Animation public education short film is an indispensable type of public expression in the new media environment. Creative and well-produced animation public education short film can reach the heart of the heart. Based on the tolerant dimension of animation public welfare education short film to the times, it not only has the positive energy transmission of mainstream public welfare culture, but also needs to cater to the entertainment Carnival of public welfare taste. Therefore, it is the core of this paper to analyze the cultural status of animation public education short film, find out the lack of animation public education culture, and how to make animation public education short film bear cultural responsibility and sustainable development, so as to provide some new ideas and comments for the future development of animation public education short film.

\section{Features of Animation Public Education Short Film}

Animation public education short film includes animation public advertising, animation public micro film and other forms of expression. Therefore, animation public education short film has the nature of both. Animation public welfare education short film uses virtual cartoon characters as the main symbols, and uses exaggerated expression techniques to express the real story. Animation public 
welfare education short film has opened up a new narrative mode for the traditional real life public welfare short film and created a new pseudo symbol.

The influence of the characteristics of communication under the traditional media is not so large, and the awareness is not wide enough. The new characteristics of communication under the new media and the new micro form carry the new morality. In 1981, the animation short film "three monks" was produced by Shanghai art studio, which is 15 minutes long. It recreates the virtual image of short monk, tall monk, fat monk and bucket shoulder pole with real and simple lines. The story revolves around their need to go to the temple, When the three monks in the temple compare with each other and don't want to fetch water, Guanyin closes his eyes when they sit on their backs and face empty tanks, buckets and shoulder poles. When the three fight for a little water left in the bottle, Guanyin opens his eyes and frowns angrily. As an outsider of the "fetching event", Guanyin's exaggerated expression reflects that he is a just guest The main body of the temple is helpless with the "water pumping event". When the naughty, anthropomorphic mice make a squeak of laughter, which makes the audience laugh and at the same time makes the audience reflect on themselves. The little mouse jumped up and down and knocked over the stove, causing a fire in the temple, but there was no water in the temple. The three monks chose to work together to fight the fire with water. The pictures and high-frequency music set off the tense atmosphere of fighting the fire. Such an atmosphere drives the audience's mood and conveys to the audience that unity is the central idea of strength. In "three monks" animation public welfare education short film, "Guanyin" and "mouse" mimicry expression can more bring into the audience's mood, make the audience have a pleasant feeling, let the audience and the story of the short film breathe together, and then better spread the socialist core values, and pass the positive energy to the audience.

Multimodal metaphor is also a unique way of expression in animation public welfare short films. Multimodal metaphor is the anthropomorphic expression of images, sounds, languages, etc. metaphor is everywhere in animation public welfare education short film "Little Tadpole Looking for mother". In 1960, the 13 minute "Little Tadpole Looking for his mother" produced by Shanghai fine arts film studio was the first Chinese ink animation education short film. The film tells us that the frog mother left after giving birth to the tadpole eggs. The tadpole eggs gradually grow their tails and become a group of small tadpoles. After the prawn father-in-law described their mother's characteristics, they decided to find their mother. In the process of finding their mother, they mistakenly regard goldfish, crabs, tortoises and catfish as their mother, In the process of finding their mother, the tadpoles explained their own physiological changes and told the story of how they corrected themselves and recognized themselves in their mistakes. The tadpoles successfully found their mother.

Animation public education short film uses the symbolic expression of the main image and the effective means of multimodal metaphor to carry out "micro" narrative. Animation public education short film endows each image with different imagination and thinking space. The whole process conforms to the instantaneous aesthetic law of public education short film. The audience's watching experience is easy and humorous, and the content conveyed is accurate and natural, reaching to the deep heart like spring breeze and rain. Animation public education short film just has the above characteristics, in order to imperceptibly play a role of persuasion and prompt.

\section{Problems of Animation Public Education Short Films in China at this Stage}

\subsection{Small Quantity, Small Scale and Single Issuer}

Although there are several typical representative works of animation short films, the total base is low. China's national quality has been steadily improved, which also requires that the content of animation public education short films we make be more extensive and comprehensive. However, at present, the overall number of animation public education short films in China is small, and the production team behind the animation public education short films is not standardized, which will affect the communication strength of animation public education short films. In recent years, the main issuers of animation public welfare education short films in China are: national government departments spread some national policies and laws and regulations in the form of public welfare 
short films, so that the people can understand the relevant policies and laws in China, but most of these types of public welfare short films are supervised by departments, which can be explained clearly but not expressed vividly.

\subsection{Lack of Cultural Content and Creativity}

At present, the content of animation public education short film in China is simple and the source of creativity is insufficient. The content and creativity mainly rely on the important competitions, film exhibitions and art exhibitions in Colleges and universities. The creative source group is lively but not mature. The overall animation public education short film creativity is relatively single and does not integrate the traditional aesthetic art.

The producer's one-sided understanding of public welfare, weak ductility based on the response to national slogans, lack of sincerity in the presentation of specific content, single form, unable to arouse the audience's resonance, unable to touch the audience's heart.

\subsection{Rough Manufacturing, Technical Problems}

People who are proficient in all kinds of software production may not have novel ideas, creative people may not have superb skills, there is always a gap between the expression of ideas and the actual finished products, and it is a small probability time to balance the two.

\subsection{Big Blind Spot, Single Form, Simple}

In the animation public welfare short films, the number of animation public welfare short films with more than 5 minutes is too small. There are fewer animation public education short films with strong narrative plot. There are big blind spots in the number and production of animation public education short films, such as "tadpole looking for mother" and "three monks", which are 15 minutes or so, with strong moral and thought-provoking. In the new media environment, we pursue the short animation public education short film, but also means to sacrifice the narrative of the original fable.

\section{Solutions}

\subsection{Distinguish Audiences and Platforms}

For the infant period, their understanding is limited, and they can use some simple twodimensional animation to express public welfare ideas. For adults with higher aesthetic, animation public education video can be more sophisticated. In addition to animating different dimensions for different audiences, we can also differentiate platforms to express public welfare ideas,

\subsection{Creative Competition and Production Competition of Animation Public Education Short Film}

Facing the future, we must put our vision wider and wider, the dimension and environment of the possibility of producing works. Creativity is the soul of animation public service advertising. Animation public service advertising is the first one, but at this stage, the competition is directly presented through team cooperation. Then we can carry out animation public service education short film production script or design competition, first let the creativity "jump out", after screening, and then design according to different audiences, which is equivalent toIntegrate the resources together, first analyze and then make, so that the short audience effect of animation public welfare education is better, and the production efficiency will be higher.

\subsection{Eliminate the Short Film Environment of Animation Public Education and Improve the Animation Quality}

At present, we search for animation public education short films on major websites, and the relevant links and websites are too confusing, and the overall quality of animation films is uneven. It 
is suggested that a responsible department should be set up to store the excellent animation public welfare short films in the station, which is conducive to the latter's reference and inheritance.

\subsection{Deepen the Richness of Social and Cultural Connotation of the Theme}

The close combination of culture and life makes life full of appreciation of taste and beauty. We should use animation to show the details of life, so as to convey the educational significance more deeply into the people's hearts.

\section{Summary}

To solve the problem of animation public education short film in our country and make it develop towards the trend of quantity, quality and excellence is our eternal topic.

\section{References}

[1]. Mingmin Zhuo, Sanjiang Wei flash CS5 advanced course. 2013, p5-30.

[2]. Ze hong Pan. Introduction to public service advertising [M] Beijing: China Radio and television press, 2001.

[3]. Jin Tang. Analysis of modern public service advertising [M] Shanghai. East China University Press, 2012. 